\title{
6-minute walk distance is an independent predictor of mortality in patients with idiopathic pulmonary fibrosis
}

\author{
Roland M. du Bois ${ }^{1}$, Carlo Albera ${ }^{2}$, Williamson Z. Bradford ${ }^{3}$, Ulrich Costabel ${ }^{4}$, \\ Jonathan A. Leff ${ }^{3}$, Paul W. Noble ${ }^{5}$, Steven A. Sahn ${ }^{6}$, Dominique Valeyre?, \\ Derek Weycker ${ }^{8}$ and Talmadge E. King $\mathrm{Jr}^{9}$
}

Affiliations: ${ }^{1}$ Imperial College London, London, UK. ${ }^{2}$ University of Turin, Turin, Italy. ${ }^{3}$ InterMune Inc., Brisbane, CA, USA. ${ }^{4}$ Ruhrlandklinik, Essen, Germany. ${ }^{5}$ Cedars Sinai Medical Center, Los Angeles, CA, USA. ${ }^{6}$ Medical University of South Carolina, Charleston, SC, USA. ${ }^{7}$ Assistance Publique-Hôpitaux, Paris, France. ${ }^{8}$ Policy Analysis Inc., Brookline, MA, USA. 'University of California, San Francisco, CA, USA.

Correspondence: R.M. du Bois, Imperial College, London W2 1PG, UK. E-mail: ronadu-bois.co.uk

ABSTRACT 6-min walk distance (6MWD) has recently been shown to be associated with the risk of mortality in patients with idiopathic pulmonary fibrosis (IPF); however, the independent contribution of $6 \mathrm{MWD}$ to the prediction of mortality risk has not been evaluated in a large, well-defined population of patients with IPF.

A Cox proportional hazards model was used to characterise the relationship between risk factors of interest and all-cause mortality in IPF patients who completed a week 24 study visit in a clinical trial evaluating interferon $\gamma-1 b(n=748)$. Risk factors of interest included the independent predictors of mortality in the previously published clinical prediction model together with 6MWD and 24-week change in 6MWD.

Baseline 6MWD $<250 \mathrm{~m}$ was associated with a two-fold increase in the risk of mortality (hazard ratio $2.12,95 \%$ CI 1.15-3.92) and a 24 -week decline in $6 \mathrm{MWD}>50 \mathrm{~m}$ was associated with a nearly threefold increase in mortality risk (hazard ratio 2.73 ; 95\% CI 1.60-4.66). Inclusion of 6MWD data improved model discrimination compared with the original model (C-statistic 0.80 (95\% CI 0.76-0.85) versus 0.75 $(0.71-0.79))$.

Both 6MWD and change in 6MWD are independent predictors of mortality in patients with IPF. The addition of $6 \mathrm{MWD}$ to the clinical prediction model improves model discrimination compared with the original model.

@ERSpublications

6MWD indices independently predict mortality in IPF and improve performance of previous clinical prediction model http://ow.ly/tDdmP

For editorial comments see page 1237.

This article has supplementary material available from www.erj.ersjournals.com

Received: July 302013 | Accepted after revision: Nov 012013 | First published online: Dec 052013

Clinical trial: This study is registered at www.clinicaltrials.gov with identifier number NCT00075998.

Support statement: The study was sponsored by InterMune Inc. (Brisbane, CA, USA).

Conflict of interest: Disclosures can be found alongside the online version of this article at www.erj.ersjournals.com

Copyright (CERS 2014 


\section{Introduction}

Idiopathic pulmonary fibrosis (IPF) is a chronic and ultimately fatal fibrotic lung disease characterised by progressive pulmonary insufficiency and diminished exercise capacity [1]. Periods of transient clinical stability may occur; however, continued disease progression is inevitable [2]. The prognosis is poor, with an estimated 5-year survival rate that is comparable to several neoplastic disorders, including cancers of the lung, liver and brain $[3,4]$.

Several studies have identified independent predictors of mortality in patients with IPF, including age, respiratory hospitalisation, forced vital capacity (FVC) \% predicted, and longitudinal change in FVC \% pred [5-16]. The 6-min walk distance (6MWD), a practical and widely used measure of clinical status in patients with a variety of cardiopulmonary diseases [17-22], has recently been shown to be associated with the risk of mortality in patients with IPF [23-25]; however, the independent contribution of 6MWD to the risk of mortality has not been formally evaluated in a large, well-defined population of patients with IPF.

We previously reported the test performance characteristics of the 6-min walk test (6MWT) in patients with IPF [23]. A novel finding of our study was the observation that 6MWD and 24-week change in 6MWD were highly predictive of 1-year mortality despite relatively weak correlations between 6MWD and various measures of pulmonary function known to be independent predictors of mortality. Based on this observation, we hypothesised that the 6MWT might interrogate a separate domain of the disease process and provide incrementally informative data regarding the prognosis of patients with IPF. The aim of the present study, therefore, was as follows. 1) To evaluate the contribution of 6MWD to the prediction of risk of all-cause mortality in patients with IPF, independent of other indices we have previously reported to predict mortality; and 2) to assess the change in model performance when 6MWD is added to the previously published clinical model [7].

\section{Methods}

\section{Source and study populations}

The source population included all randomised patients in a prospective, double-blind, placebo-controlled phase 3 trial evaluating treatment with interferon $\gamma$-1b in patients with IPF (GIPF-007 (INSPIRE) trial; $\mathrm{n}=826$ ) [26]. From the source population, we selected for inclusion all patients who completed a baseline and week 24 study visit $(n=748)$; patients who died $(n=20)$ or had a lung transplant $(n=1)$ between baseline and week 24 were thus excluded from the analysis. Clinical efficacy outcomes in the original trial revealed no evidence of a treatment effect; therefore, the analysis included data from both treatment groups to maximise study power [26].

Criteria for enrolment in the original trial have been previously described [26]. Briefly, eligible patients had a confident IPF diagnosis according to the criteria of the American Thoracic Society/European Respiratory Society $[27,28]$, FVC $\geqslant 55 \%$ of the predicted value, diffusing capacity of the lung for carbon monoxide $(D$ LCO $) \geqslant 35 \%$ of predicted, either FVC or DLCO $\leqslant 90 \%$ of predicted, and a 6MWT distance $\geqslant 150 \mathrm{~m}$. Patients with a history of unstable or deteriorating cardiac, vascular or neurological disease within the previous 6 months and patients on a waiting list for lung transplantation at the time of randomisation were excluded from enrolment.

\section{Study protocol}

Eligible patients underwent a complete physical examination and assessments of physiological function (FVC, DLCO and resting alveolar-arterial gradient), dyspnoea (according to the University of California San Diego Shortness of Breath Questionnaire), health-related quality of life (according to St George's Respiratory Questionnaire) and exercise capacity (6MWT) at the baseline study visit and at 24-week intervals thereafter.

The 6MWT was performed indoors on a flat, straight corridor with a hard surface. An oxygen titration procedure was performed at the screening visit to establish a baseline flow rate for patients who required supplemental oxygen; all subsequent tests during the study period were performed using the baseline oxygen flow rate established during the titration procedure. Before each 6MWT, patients were required to have resting oxygen saturation as measured by pulse oximetry of at least $83 \%$ after 10 min of rest breathing room air or at the baseline $\mathrm{O}_{2}$ flow rate. Patients were instructed to walk as far as they could without jogging or running; if they needed to slow down or stop to rest they were permitted to do so and encouraged to resume walking as soon as they were able. The test was stopped if the patient experienced chest pain, intolerable dyspnoea, leg cramps, diaphoresis or desaturation below $83 \%$.

Two observation periods were used to maximise the number of events and enhance the power of the study to detect significant relationships between predictor variables and 1-year mortality. Predictors of mortality were assessed during the period from the trial baseline to the week 24 trial visit, and during the period from 
INSPIRE trial (source data)

Mortality predictors study

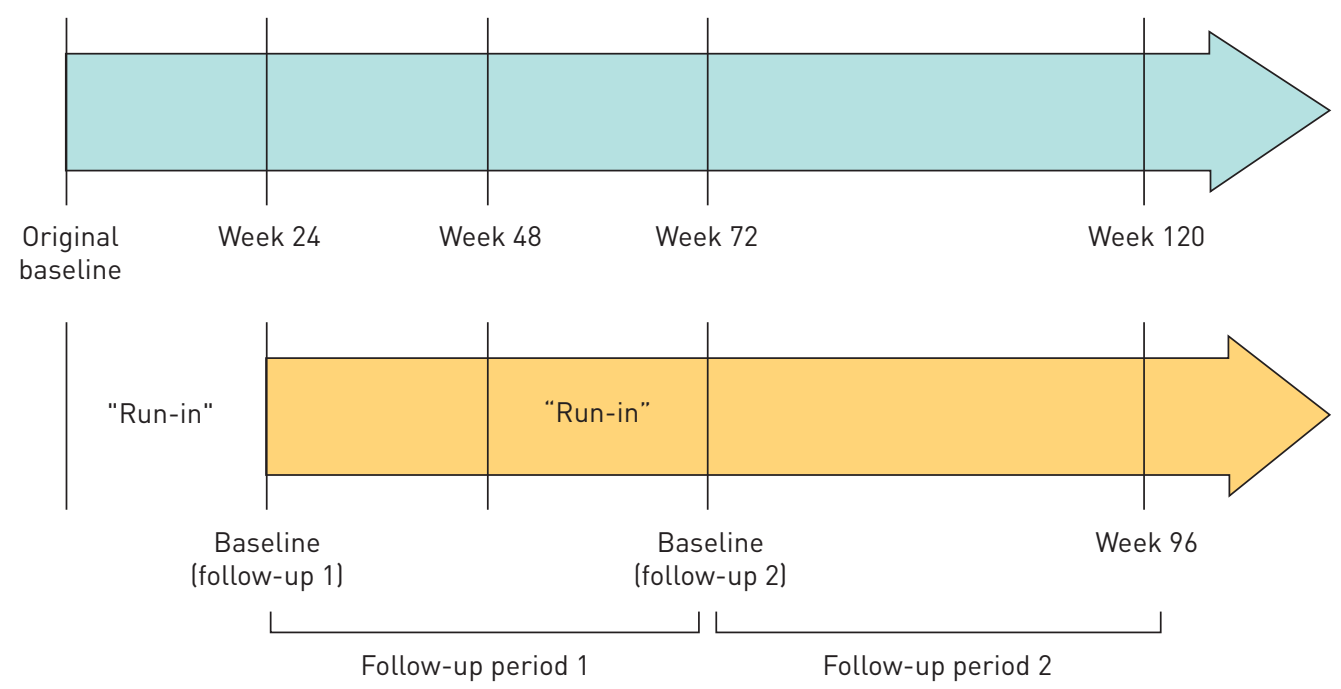

FIGURE 1 Schematic of study design.

the week 48 to the week 72 trial visits, respectively. These periods served as the "run-in" phases during which changes in longitudinal predictors of mortality were measured; all deaths occurring over the subsequent 48-week periods were identified and flagged accordingly (fig. 1). All data from the two periods were pooled into a single dataset for analysis; therefore, patients may have contributed up to two unique observations to the study database.

\section{Statistical analysis}

A multivariate Cox proportional hazards model was used to characterise the relationship between risk factors of interest and all-cause mortality. Risk factors of interest included the independent predictors of mortality in the previously published clinical model (age, respiratory hospitalisation, FVC \% pred and 24-week change in FVC \% pred) [7], as well as 6MWD and 24-week change in 6MWD. Categorical thresholds were retained for risk factors of interest from the original clinical model; categorical thresholds for baseline 6MWD and 24-week change in 6MWD were selected based on prior research [23].

The presence of multicollinearity, hazards assumptions and model discrimination were evaluated using published methods $[29,30]$. Model discrimination was quantified based on the C-statistic and compared against the previously published clinical model. The C-statistic is a measure of the probability that among two randomly selected patients the patient with the higher predicted risk of an event will be the first to experience the event. Values range from 0.5 (model discrimination is no better than chance) to 1.0 (perfect discrimination). Values between 0.70 and 0.80 were assumed to signify "acceptable" model discrimination; values exceeding 0.80 were assumed to represent "excellent" discrimination. Model performance was also evaluated by calculating the net reclassification improvement (NRI) for the model including 6MWD and change in 6MWD compared with the original model (based on patients in study GIPF-007). The NRI can be quantified as a sum of differences in proportions of individuals moving up in risk categories minus the proportion moving down for subjects who develop events, and the proportion of individuals moving down minus the proportion moving up for people who do not develop events [30].

\section{Results}

A total of 748 patients completed a week 24 study visit in the original clinical trial and therefore qualified for inclusion in the study population. Demographics and baseline characteristics are summarised in table 1. The mean \pm SD age at study entry was $66 \pm 7.6$ years and $71.5 \%$ of patients were male. Mean values for FVC $\%$ pred and DLCO \% pred were $72.5 \pm 12.8$ and $47.5 \pm 9.2$, respectively. The mean \pm SD distance walked during the $6 \mathrm{MWT}$ was $397 \pm 107 \mathrm{~m}$. A total of $86(11.5 \%)$ patients required supplemental oxygen during the $6 \mathrm{MWT}$; among these, the mean baseline oxygen flow rate was $2.84 \mathrm{~L} \cdot \mathrm{min}^{-1}$.

There was a total of 79 deaths during the two periods of observation ( $\mathrm{n}$ (patient visits)=1156; see online supplementary table E1); 59 deaths occurred between the week 24 and week 72 study visits (mean duration 


\section{TABLE 1 Demographics and baseline characteristics}

$\begin{array}{lc}\text { Subjects } \mathbf{n} & 748 \\ \text { Age years } & 66 \pm 7.6 \\ \text { Sex } & \\ \quad \text { Male } & 535(71.5) \\ \text { Female } & 213(28.5) \\ \text { Ethnicity } & \\ \quad \text { Caucasian } & 703(94.0) \\ \quad \text { Other } & 45(6.0) \\ \text { Country of residence } & 521(69.7) \\ \quad \text { USA } & 227(30.3) \\ \text { Other } & \\ \text { Treatment assignment } & 496(66.3) \\ \quad \text { Interferon } \gamma \text {-1b } & 252(33.7) \\ \text { Placebo } & \\ \text { Clinical } & 653(87.3) \\ \quad \text { Honeycombing on HRCT } & 411(54.9) \\ \text { Surgical lung biopsy } & 213(28.5) \\ \text { History of cardiovascular disease } & 115(15.4) \\ \text { Supplemental oxygen use } & \\ \text { Physiological characteristics } & 72.5 \pm 12.8 \\ \text { FVC \% predicted } & 47.5 \pm 9.2 \\ \text { DLCo \% predicted } & 397 \pm 107 \\ \text { 6MWT distance m } & \end{array}$

Data are presented as mean \pm SD or $\mathrm{n}(\%)$. HRCT: high-resolution computed tomography; FVC: forced vital capacity; DLCO: diffusing capacity of the lung for carbon monoxide; 6MWT: 6-min walk test.

of follow-up, 43 weeks) and 20 deaths occurred during the 48 -week period following the week 72 study visit (mean duration of follow-up, 31 weeks). The crude 1-year risk of all-cause mortality was 6.8\% (95\% CI 5.4-8.3\%). Death was judged by clinical investigators to be IPF-related in 67 patients (crude 1-year risk $5.8 \%, 95 \%$ CI $4.6-7.1 \%)$.

The unadjusted risk of 1-year all-cause mortality and Kaplan-Meier survival distributions by baseline 6MWD and 24-week change in 6MWD are summarised in table 2 and figure 2, respectively. In the unadjusted analyses, both baseline 6MWD and 24-week change in 6MWD were associated with the risk of 1-year mortality. Patients with a $>50 \mathrm{~m}$ decline in 6MWD at 24 weeks (versus $\leqslant 25 \mathrm{~m}$ decline) had the largest relative risk (hazard ratio (HR) 3.76, 95\% CI 2.26-6.27; $\mathrm{p}<0.001$ ).

In the multivariate analysis, all risk factors of interest were found to be statistically significant independent predictors of all-cause mortality, including age, respiratory hospitalisation, FVC \% pred, 6MWD and 24 -week changes in FVC \% pred and 6MWD (table 3). Baseline $6 \mathrm{MWD}<250 \mathrm{~m}$ was independently associated with a two-fold increase in the risk of 1-year mortality (HR 2.12, 95\% CI 1.15-3.92; p $=0.02$ ) and a 24-week decrement in $6 \mathrm{MWD}>50 \mathrm{~m}$ was independently associated with a nearly three-fold increase in the risk of mortality at 1 year (HR 2.73, 95\% CI 1.60-4.66; $\mathrm{p}<0.01$ ). Additionally, inclusion of $6 \mathrm{MWD}$ and 24 -week change in $6 \mathrm{MWD}$ improved model discrimination compared with the original clinical model

TABLE 2 Unadjusted 1-year risk of all-cause mortality by baseline 6-min walk distance (6MWD) and 24-week change in 6MWD

\begin{tabular}{cccc}
$\begin{array}{c}\text { Patient } \\
\text { visits } \mathbf{n}\end{array}$ & $\begin{array}{c}\text { Deaths } \\
\mathbf{n}(\%)\end{array}$ & $\begin{array}{c}\text { Hazard ratio } \\
(\mathbf{9 5 \%} \mathbf{~ C l )}\end{array}$ & p-value \\
& & & \\
125 & $15(12.0)$ & $2.33(1.30-4.18)$ & 0.005 \\
244 & $19(7.8)$ & $1.42(0.83-2.43)$ & 0.201 \\
787 & $45(5.7)$ & 1.00 & \\
308 & $38(12.3)$ & $3.76(2.26-6.27)$ & $<0.001$ \\
165 & $17(10.3)$ & $3.15(1.69-5.86)$ & $<0.001$ \\
683 & $24(3.5)$ & 1.00 & \\
\hline
\end{tabular}





FIGURE 2 Kaplan-Meier survival distribution by a) baseline 6-min walk distance (6MWD) and b) 24-week change in 6MWD. p-values are from the Log-rank test.

(C-statistic 0.80 (95\% CI 0.76-0.85) versus 0.75 (95\% CI 0.71-0.79)). The addition of 6MWD and 24-week change in 6MWD to the original model resulted in a NRI of $26.1 \%(\mathrm{p}<0.001) ; 10.1 \%$ of events and $16.0 \%$ of nonevents were reclassified correctly compared with the original model (table 4).

Hazard ratios for risk factors of interest from the original clinical model were comparable to previously published estimates. Consistent with the original clinical model, FVC \% pred and 24 -week change in FVC \% pred remained the most important predictors of 1-year mortality; the hazard ratio for all-cause mortality was $6.86(95 \%$ CI 1.99-23.60) $(\mathrm{p}<0.01)$ among patients with a baseline FVC $\leqslant 50 \%($ versus $\geqslant 80 \%)$ and $5.86(95 \%$ CI 3.33-10.81) $(\mathrm{p}<0.01)$ among patients with $\mathrm{a} \geqslant 10 \%$ decline in FVC at 24 weeks (versus $>-5 \%)$.

As the original clinical model included a subset of 330 patients from the GIPF-001 study for whom 6MWT data were not collected, a multivariate analysis using the predictor variables in the original clinical model was repeated in the subset of patients $(n=748)$ who were included in the present analysis (online supplementary table E2). Hazard ratios and model discrimination were largely unchanged compared with the original clinical model. Consistent with the original clinical model, the addition of 6MWD and change in 6MWD improved model discrimination in this cohort (C-statistic 0.80 (95\% CI 0.76-0.85) versus 0.76 $(0.71-0.82))$.

\section{Discussion}

The hallmark clinical features of IPF include progressive pulmonary insufficiency and reduced exercise capacity. While declines in lung function and exercise capacity are inevitable, considerable variability may be observed in the rate of disease progression, both within and between patients. Moreover, longitudinal changes in the various measures used to assess clinical status in patients with IPF are only weakly correlated; periods of transient stability in one measure may coincide with marked declines in others [23, 31]. As a result of the highly variable and enigmatic clinical course, formulating an accurate prognosis in the individual patient represents a distinct challenge for clinicians. The identification of accurate predictors of mortality that are readily and reliably ascertainable in the typical clinical setting, therefore, has obvious and important implications for the clinical management of patients with IPF.

We previously reported that a simplified clinical risk prediction model comprised of four predictors that are widely accessible in the clinical setting accurately predicts near-term mortality in patients with IPF [7]. The predictors included age, history of respiratory hospitalisation within the preceding 24 weeks, FVC \% pred and 24-week change in FVC \% pred. In the present study, we further demonstrate that 6MWD and 24-week change in 6MWD are independent predictors of near-term mortality in patients with IPF and that a novel clinical risk prediction model comprised of age, respiratory hospitalisation, FVC \% pred, 6MWD and 24-week changes in FVC \% pred and 6MWD improves the ability to discriminate between patients on the basis of risk compared with the previously published clinical model.

The 6MWT has several potential advantages as a measure of clinical status in patients with IPF. The test is practical, inexpensive and reliable; it requires no special equipment or advanced training and can be performed by all but the most severely impaired patients [32]. Additionally, 6MWD is highly reproducible in patients with IPF $[23,33]$ and changes in $6 \mathrm{MWD}$ have been shown to correlate with changes in measures of physiological function and health-related quality of life [23]. As the 6MWT is self-paced, it is both better tolerated and more reflective of activities of daily living than other walk tests [34]. Finally, the 6MWT may 
TABLE 3 Multivariate analysis of predictors of all-cause mortality in patients with idiopathic pulmonary fibrosis

\begin{tabular}{|c|c|c|c|c|}
\hline \multirow[t]{2}{*}{ Predictor variable } & \multicolumn{2}{|c|}{ Original clinical model $[7]^{\#}$} & \multicolumn{2}{|c|}{ Novel clinical model ${ }^{\pi}$} \\
\hline & Hazard ratio $(95 \% \mathrm{Cl})$ & p-value & Hazard ratio $(95 \% \mathrm{Cl})$ & p-value \\
\hline \multicolumn{5}{|l|}{ Age years } \\
\hline$\geqslant 70$ & $2.21(1.35-3.62)$ & 0.002 & $2.35(1.14-4.82)$ & 0.02 \\
\hline $60-69$ & $1.49(0.90-2.46)$ & 0.12 & $2.29(1.13-4.63)$ & 0.02 \\
\hline$<60$ & 1.00 & & 1.00 & \\
\hline Respiratory hospitalisation & $4.11(2.57-6.58)$ & $<0.001$ & $3.54(1.80-6.97)$ & $<0.01$ \\
\hline \multicolumn{5}{|l|}{ Baseline FVC \% predicted } \\
\hline$\leqslant 50$ & $5.79(2.55-13.15)$ & $<0.001$ & $6.86(1.99-23.60)$ & $<0.01$ \\
\hline $51-65$ & $3.54(1.95-6.44)$ & $<0.001$ & $2.92(1.39-6.13)$ & $<0.01$ \\
\hline $66-79$ & $2.20(1.19-4.09)$ & 0.012 & $2.17(1.02-4.63)$ & 0.05 \\
\hline$\geqslant 80$ & 1.00 & & 1.00 & \\
\hline \multicolumn{5}{|l|}{$\begin{array}{l}\text { 24-week change in FVC \% } \\
\text { predicted }\end{array}$} \\
\hline$\leqslant-10$ & $7.99(5.26-12.14)$ & $<0.001$ & $5.86(3.33-10.81)$ & $<0.01$ \\
\hline$-5--9.9$ & $2.60(1.75-3.85)$ & $<0.001$ & $2.74(1.61-4.68)$ & $<0.01$ \\
\hline$>-5$ & 1.00 & & 1.00 & \\
\hline \multicolumn{5}{|l|}{ Baseline 6MWD $\mathrm{m}$} \\
\hline$<250$ & & & $2.12(1.15-3.92)$ & 0.02 \\
\hline $250-349$ & & & $1.28(0.74-2.21)$ & 0.38 \\
\hline$\geqslant 350$ & & & 1.00 & \\
\hline \multicolumn{5}{|l|}{ 24-week change in 6MWD m } \\
\hline$<-50$ & & & $2.73(1.60-4.66)$ & $<0.01$ \\
\hline$-50--26$ & & & $2.94(1.56-5.53)$ & $<0.01$ \\
\hline$\geqslant-25$ & & & 1.00 & \\
\hline C-statistic $(95 \% \mathrm{Cl})$ & 0.75 (0.71-0.79) & & $0.80(0.76-0.85)$ & \\
\hline
\end{tabular}

FVC: forced vital capacity; 6 MWD: 6 -min walk distance. ${ }^{\#}$ : patient visits $n=1854$, deaths $n=142$; ${ }^{9}$ : patient visits $n=1156$, deaths $n=79$.

be incrementally informative in the assessment of disease progression in IPF patients with comorbid emphysema by capturing functional deficits that would otherwise be masked due to the spurious preservation of FVC [33].

Only two previous studies have demonstrated an independent association between 6MWD and the risk of mortality in patients with IPF [24, 25]. In a retrospective review of data from 44 patients with IPF, 29 of whom had an additional evaluation at 12 months, CAMINATI et al. [24] reported that both baseline 6MWD $(<212 \mathrm{~m})$ and change in 6MWD at 12 months were independently associated with an increased risk of mortality. The study was limited by the modest sample size and the retrospective nature of the analysis, as well as the exclusion of patients who were unable to perform the 6MWT without the use of supplemental oxygen. However, the findings were generally consistent with a previous study by LEDERER et al. [25] that evaluated the prognostic utility of 6MWD in 454 patients with IPF who were on a waiting list for lung transplantation. In this study, baseline 6 MWD $(<207 \mathrm{~m})$ was strongly and independently associated with an increased risk of mortality at 6 months and performed better than baseline FVC \% pred as a predictor of waiting list survival. It is of note that longitudinal change in 6MWD was not evaluated as a potential predictor of mortality, and the 6MWT was not performed according to a standardised protocol across study sites. Moreover, patients listed for lung transplantation represent a distinct cohort; on average, patients in this study were younger and had more severe physiological impairment and a higher prevalence of comorbid pulmonary hypertension than IPF patients who are not candidates for lung transplantation. As a result, the degree to which the findings can be generalised to the broader population of patients with IPF is unknown.

In the present analysis, we examined the specific contribution of 6MWD to the risk of near-term mortality in a large and well-defined population of patients with a confident diagnosis of IPF and broad range of impairment in physiological measures of disease status. Baseline $6 \mathrm{MWD}<250 \mathrm{~m}$ was independently associated with a two-fold increase in the risk of 1-year mortality, and a $50 \mathrm{~m}$ decrement in $6 \mathrm{MWD}$ at 24 weeks conferred a nearly three-fold increase in the risk of mortality during the subsequent year, even after controlling for age, respiratory hospitalisation, FVC \% pred and 24-week change in FVC. This latter 
TABLE 4 Reclassification of patients who died and those who did not die with inclusion of baseline 6-min walk distance (6MWD) and 24 -week change in 6MWD\#

\begin{tabular}{|c|c|c|c|c|}
\hline \multirow[t]{2}{*}{ Model without 6MWD/ $6 \mathrm{MWD}$ : predicted mortality risk } & \multicolumn{4}{|c|}{ Model with $6 \mathrm{MWD} / \triangle 6 \mathrm{MWD}$ : predicted mortality risk } \\
\hline & $<0.02$ & $0.02-0.04$ & $0.04-0.07$ & $\geqslant 0.07$ \\
\hline \multicolumn{5}{|l|}{ Patients who died } \\
\hline$<0.02$ & 16 & 2 & 0 & 0 \\
\hline $0.02-0.04$ & 2 & 12 & 4 & 3 \\
\hline $0.04-0.07$ & 0 & 4 & 4 & 6 \\
\hline$<0.02$ & 234 & 47 & 3 & 0 \\
\hline $0.02-0.04$ & 103 & 112 & 32 & 9 \\
\hline $0.04-0.07$ & 0 & 178 & 29 & 82 \\
\hline$\geqslant 0.07$ & 0 & 29 & 35 & 184 \\
\hline \multicolumn{5}{|l|}{ Summary } \\
\hline
\end{tabular}



finding is particularly noteworthy, as it establishes for the first time in a large, multinational study that longitudinal change in 6MWD is strongly and independently associated with the risk of near-term mortality in patients with IPF. While our results also demonstrated a significant relationship between a 24-week decrement in $6 \mathrm{MWD}$ of $26-50 \mathrm{~m}$ and the risk of 1-year mortality, we chose to focus on the threshold of a $50 \mathrm{~m}$ decrement based on prior work in which the minimal clinically important difference for the 6MWT was estimated as 24-45 m [23]. We selected the higher threshold because we did not wish to sacrifice specificity in order to improve sensitivity.

A further noteworthy finding of this study is the observation that the addition of 6MWD to a parsimonious clinical model based on four widely available and inexpensive measures of disease status provides data that is incrementally informative in the prognostic evaluation of individual patients with IPF. Model discrimination, as measured by the C-statistic, improved from 0.75 ( $95 \%$ CI $0.71-0.81$ ) to 0.80 (95\% CI 0.76-0.85) when 6MWD and 24-week change in 6MWD were added to a model comprised of age, respiratory hospitalisation, FVC \% pred and 24-week change in FVC \% pred. The magnitude of improvement in model discrimination is notable, as large independent associations with the dependent variable are required for the addition of a predictive marker to result in a meaningful increase in the Cstatistic [29]. For example, Pencina et al. [29] evaluated the improvement in model performance by the introduction of high-density lipoprotein (HDL) cholesterol into a standard prediction model for a first coronary heart disease (CHD) event in 3264 subjects who were part of the Framingham Heart Study. HDL cholesterol was independently associated with the risk of a CHD event (HR 0.64; $<<0.001$ ); however, the addition of HDL cholesterol to a standard model comprised of age, sex, smoking status and systolic blood pressure had a negligible effect on model discrimination (C-statistic 0.77 versus $0.76 ; \mathrm{p}=$ nonsignificant). In

TABLE 5 Model discrimination for selected cardiovascular risk prediction models based on the Framingham Heart Study

\begin{tabular}{lcc} 
Risk prediction model & Subjects n & C-statistic \\
\hline Framingham Heart Study General Cardiovascular Risk [35] & 8491 & $0.76-0.79$ \\
Framingham Heart Study Atrial Fibrillation Risk [36] & 4764 & 0.78 \\
Incident Heart Failure Risk in the Elderly [37] & 2935 & 0.73 \\
Framingham Stroke Risk in Patients with Atrial Fibrillation [38] & 868 & 0.66 \\
TIMI ST-elevation Myocardial Infarction (STEMI) Risk Score [39] & 47882 & 0.67 \\
\hline
\end{tabular}

TIMI: thrombolysis in myocardial infarction. 
addition, consistent with the original clinical model, the discriminative ability of the novel model compared favourably with several well-established cardiovascular disease models based on the Framingham Heart Study; C-statistics for these models ranged from 0.66-0.79 (table 5) [35-39].

Our findings have several potential implications for both clinical practice and clinical trial design. The $6 \mathrm{MWT}$ is a practical, safe and inexpensive measure that can be performed in virtually any setting without the need for specialised equipment or advanced training. Our results demonstrate that data obtained from this simple and inexpensive test can be used to further inform prognosis and facilitate clinical decision making. Additionally, the ability to further discriminate between patients on the basis of risk may facilitate refinement of enrolment criteria for therapeutic clinical trials, thereby enriching study populations and potentially decreasing the necessary size, duration and cost of clinical trials. Finally, the strong independent association between longitudinal changes in FVC and 6MWD and the risk of mortality, coupled with the favourable test performance characteristics and relatively weak correlations between changes in FVC and $6 \mathrm{MWD}$ suggest that a composite end-point for disease progression defined on the basis of categorical change in FVC and 6MWD might substantially increase the rate of clinically meaningful events and further improve the efficiency of clinical trials.

The findings of our study should be interpreted in the context of several important limitations. First, source data for our analysis was obtained from a clinical trial that enrolled patients with mild-to-moderate impairment in baseline measures of lung function and exercise capacity. Patients with severe functional impairment or those with selected comorbidities including severe emphysema and unstable cardiovascular disease were excluded from enrolment. While the study population probably included patients with mildto-moderate emphysema, as well as patients who developed severe impairment in physiological function during the interval preceding the second observation period (week 72 to week 120), the degree to which our findings can be generalised to these populations is uncertain.

Secondly, risk factors of interest and the corresponding categorical thresholds in our model were identified a priori based on prior research. Since the primary aims of the study were to assess the independent contribution of 6MWD to the risk of mortality and evaluate the predictive value of 6MWD when added to the previously published clinical prediction model, no formal model specification procedures were undertaken in the primary analysis to specify the model de novo. Thirdly, as noted in our prior publication [7], hospitalisations were designated as respiratory in nature based on the clinical judgment of the primary investigator and were not formally adjudicated. We note, however, that our original intent was to develop a risk prediction model that could be used in the clinical setting to quickly and accurately formulate a prognosis based on readily available data. Accordingly, we believe that the manner in which hospitalisations were characterised is more reflective of typical clinical practice, thereby potentially enhancing the clinical utility of the model. Finally, the 6MWT was performed with strict adherence to a standardised protocol following a formal oxygen titration procedure; the replication of such rigorous methods in the typical clinical setting, while possible, cannot be assured. Indeed, our decision not to develop a revised risk scoring system was based largely on the probable inconsistent clinical application of standardised procedures for the $6 \mathrm{MWT}$. Nonetheless, we believe that the strength of the relationship between 6MWD and the risk of mortality warrants consideration in the clinical assessment of patients with IPF and has important implications for the design and execution of clinical trials.

In conclusion, the findings of the present study demonstrate that both 6MWD and longitudinal change in $6 \mathrm{MWD}$ are strong independent predictors of mortality in patients with IPF. Additionally, a clinical risk prediction model comprised of age, respiratory hospitalisation, FVC \% pred, 6MWD and 24-week changes in FVC \% pred and 6MWD reliably predicts 1-year mortality in patients with IPF and may be used to further refine the prognosis of individual patients and guide clinical decision making. Further research is warranted to validate the model in other large and independent patient populations.

\section{Acknowledgements}

We are indebted to K. Glasscock (Intermune Inc., Brisbane, CA, USA) for medical writing and editorial assistance and to the participating staff members and patients at all study centres.

\section{References}

1 Raghu G, Collard HR, Egan JJ, et al. An official ATS/ERS/JRS/ALAT statement: idiopathic pulmonary fibrosis: evidence-based guidelines for diagnosis and management. Am J Respir Crit Care Med 2011; 183: 788-824.

2 Ley B, Collard HR, King TE Jr. Clinical course and prediction of survival in idiopathic pulmonary fibrosis. Am J Respir Crit Care Med 2011; 183: 431-440.

3 Olson AL, Swigris JJ, Lezotte DC, et al. Mortality from pulmonary fibrosis increased in the United States from 1992 to 2003. Am J Respir Crit Care Med 2007; 176: 277-284.

4 SEER cancer statistics review. Statistics based on Surveillance Epidemiology and End Results (SEER) Program 18 data (2003 to 2009) http://seer.cancer.gov Date last updated: April 15, 2009. Date last accessed: March 4, 2014. 
5 King TE Jr, Tooze JA, Schwarz MI, et al. Predicting survival in idiopathic pulmonary fibrosis: scoring system and survival model. Am J Respir Crit Care Med 2001; 164: 1171-1181.

6 Jegal Y, Kim DS, Shim TS, et al. Physiology is a stronger predictor of survival than pathology in fibrotic interstitial pneumonia. Am J Respir Crit Care Med 2005; 171: 639-644.

7 du Bois RM, Weycker D, Albera C, et al. Ascertainment of individual risk of mortality for patients with idiopathic pulmonary fibrosis. Am J Respir Crit Care Med 2011; 184: 459-466.

8 Ley B, Ryerson CJ, Vittinghoff E, et al. A multidimensional index and staging system for idiopathic pulmonary fibrosis. Ann Intern Med 2012; 156: 684-691.

9 Wells AU, Desai SR, Rubens MB, et al. Idiopathic pulmonary fibrosis: a composite physiologic index derived from disease extent observed by computed tomography. Am J Respir Crit Care Med 2003; 167: 962-969.

10 Latsi PI, du Bois RM, Nicholson AG, et al. Fibrotic idiopathic interstitial pneumonia: the prognostic value of longitudinal functional trends. Am J Respir Crit Care Med 2003; 168: 531-537.

11 Collard HR, King TE Jr, Bartelson BB, et al. Changes in clinical and physiologic variables predict survival in idiopathic pulmonary fibrosis. Am J Respir Crit Care Med 2003; 168: 538-542.

12 Flaherty KR, Mumford JA, Murray S, et al. Prognostic implications of physiologic and radiographic changes in idiopathic interstitial pneumonia. Am J Respir Crit Care Med 2003; 168: 543-548.

13 Zappala CJ, Latsi PI, Nicholson AG, et al. Marginal decline in forced vital capacity is associated with a poor outcome in idiopathic pulmonary fibrosis. Eur Respir J 2010; 35: 830-836.

14 Hook JL, Arcasoy SM, Zemmel D, et al. Titrated oxygen requirement and prognostication in idiopathic pulmonary fibrosis. Eur Respir J 2012; 39: 359-365.

15 Mura M, Porretta MA, Bargagli E, et al. Predicting survival in newly diagnosed idiopathic pulmonary fibrosis: a 3-year prospective study. Eur Respir J 2012; 40: 101-109.

16 Maldonado F, Moua T, Rajagopalan S, et al. Automated quantification of radiological patterns predicts survival in idiopathic pulmonary fibrosis. Eur Respir J 2014; 43: 204-212.

17 Lipkin DP, Scriven AJ, Crake T, et al. Six-minute walking test for assessing exercise capacity in chronic heart failure. Br Med J (Clin Res Ed) 1986; 292: 653-655.

18 Cahalin LP, Mathier MA, Semigran MJ, et al. The six-minute walk test predicts peak oxygen uptake and survival in patients with advanced heart failure. Chest 1996; 110: 325-332.

19 Gomberg-Maitland M, Huo D, Benza RL, et al. Creation of a model comparing 6-minute walk test to metabolic equivalent in evaluating treatment effects in pulmonary arterial hypertension. J Heart Lung Transplant 2007; 26: 732-738.

20 Guyatt GH, Pugsley SO, Sullivan MJ, et al. Effect of encouragement on walking test performance. Thorax 1984; 39: 818-822.

21 Bernstein ML, Despars JA, Singh NP, et al. Reanalysis of the 12-minute walk in patients with chronic obstructive pulmonary disease. Chest 1994; 105: 163-167.

22 Baughman RP, Sparkman BK, Lower EE. Six-minute walk test and health status assessment in sarcoidosis. Chest 2007; 132: 207-213.

23 du Bois RM, Weycker D, Albera C, et al. Six-minute-walk test in idiopathic pulmonary fibrosis: test validation and minimal clinically important difference. Am J Respir Crit Care Med 2011; 183: 1231-1237.

24 Caminati A, Bianchi A, Cassandro R, et al. Walking distance on 6-MWT is a prognostic factor in idiopathic pulmonary fibrosis. Respir Med 2009; 103: 117-123.

25 Lederer DJ, Arcasoy SM, Wilt JS, et al. Six-minute walk distance predicts waiting list survival in idiopathic pulmonary fibrosis. Am J Respir Crit Care Med 2006; 174: 659-664.

26 King TE Jr, Albera C, Bradford WZ, et al. Effect of interferon $\gamma-1 \mathrm{~b}$ on survival in patients with idiopathic pulmonary fibrosis (INSPIRE): a multicentre, randomised, placebo-controlled trial. Lancet 2009; 374: 222-228.

27 American Thoracic Society, European Respiratory Society. Idiopathic pulmonary fibrosis: diagnosis and treatment. International consensus statement. Am J Respir Crit Care Med 2000; 161: 646-664.

28 American Thoracic Society, European Respiratory Society. American Thoracic Society/European Respiratory Society international multidisciplinary consensus classification of the idiopathic interstitial pneumonias. Am J Respir Crit Care Med 2002; 165: 277-304.

29 Pencina MJ, D’Agostino RB Sr, D’Agostino RB Jr, et al. Evaluating the added predictive ability of a new marker: from area under the ROC curve to reclassification and beyond. Stat Med 2008; 27: 157-172.

30 Allison PD. Survival analysis using the SAS System: a practical guide. Cary, SAS Institute Inc., 1995; p. 292.

31 du Bois RM, Weycker D, Albera C, et al. Forced vital capacity in patients with idiopathic pulmonary fibrosis: test properties and minimal clinically important difference. Am J Respir Crit Care Med 2011; 184: 1382-1389.

32 American Thoracic Society. ATS Statement. Guidelines for the six-minute walk test. Am J Respir Crit Care Med 2002; 166: 111-117.

33 Eaton T, Young P, Milne D, et al. Six-minute walk, maximal exercise tests: reproducibility in fibrotic interstitial pneumonia. Am J Respir Crit Care Med 2005; 171: 1150-1157.

34 Solway S, Brooks D, Lacasse Y, et al. A qualitative systematic overview of the measurement properties of functional walk tests used in the cardiorespiratory domain. Chest 2001; 119: 256-270.

35 D’Agostino RB Sr, Vasan RS, Pencina MJ, et al. General cardiovascular risk profile for use in primary care: the Framingham Heart Study. Circulation 2008; 117: 743-753.

36 Schnabel RB, Sullivan LM, Levy D, et al. Development of a risk score for atrial fibrillation (Framingham Heart Study): a community-based cohort study. Lancet 2009; 373: 739-745.

37 Butler J, Kalogeropoulos A, Georgiopoulou V, et al. Incident heart failure prediction in the elderly: the health ABC heart failure score. Circ Heart Fail 2008; 1: 125-133.

38 Wang TJ, Massaro JM, Levy D, et al. A risk score for predicting stroke or death in individuals with new-onset atrial fibrillation in the community: the Framingham Heart Study. JAMA 2003; 290: 1049-1056.

39 Rathore SS, Weinfurt KP, Foody JM, et al. Performance of the Thrombolysis in Myocardial Infarction (TIMI) STelevation myocardial infarction risk score in a national cohort of elderly patients. Am Heart J 2005; 150: 402-410. 